\title{
Family Medicine in Cuba: Community-Oriented Primary Care and Complementary and Alternative Medicine
}

\author{
Lee T. Dresang, MD, Laurie Brebrick, FNP, Danielle Murray, MD, Ann Shallue, DO, \\ and Lisa Sullivan-Vedder, MD
}

Family physicians in Cuba and the United States operate within very different health systems. Cuba's health system is notable for achieving developed country health outcomes despite a developing country economy. The authors of this study traveled to Cuba and reviewed the literature to investigate which practices of Cuban family physicians might be applicable for US family physicians wishing to learn from the Cuban experience. We found that community-oriented primary care (COPC) and complementary and alternative medicine (CAM) are well developed within the Cuban medical system. Because COPC and CAM are already recommended by US family medicine professional bodies, US family physicians may want to learn from the Cuban experience and perhaps incorporate elements into their individual practices. (J Am Board Fam Pract 2005;18:297-303.)

A Cuban family physician typically spends the morning seeing patients in the clinic adjoining his or her house and spends the afternoon making home visits to patients in the community immediately surrounding that clinic. Given the current structure and financing of the US health system, replicating this model is not feasible for most US family physicians. However, there are some practices of Cuban family physicians that US physicians may find valuable and achievable within their individual practices.

To gain firsthand insight into the role of family physicians in Cuba, the authors of this article-a family physician, 3 family practice residents, and a family nurse practitioner-traveled to Cuba through the Medical Education Cooperation with Cuba (MEDICC) organization. With our trip to Cuba, we saw a unique opportunity to visit a developing country with the purpose of learning rather than teaching.

Submitted, revised, 8 April 2005.

From the University of Wisconsin Medical School, St. Luke's Family Practice Residency, Milwaukee (LTD, AS, LS-V), Sixteenth Street Community Health Center, Milwaukee, Wisconsin (LB), and Family Practice Specialists of Richmond, Richmond, Virginia (DM).

Conflict of interest: none declared.

Corresponding author: Lee T. Dresang, MD, $1230 \mathrm{~W}$. Grant Street, Milwaukee, WI 53215 (e-mail: ldresang@ fammed.wisc.edu).
The Cuban health system is of special interest because of its developed-country health outcomes despite its developing-country economy. Cuba spends just $7.4 \%$ of its gross national product (GNP) on health care, compared with the $13.6 \%$ spent in the United States. ${ }^{1}$ Health expenditure per person is $\$ 193$ in Cuba compared with $\$ 4540$ spent in the United States. ${ }^{2}$ Cuba's GNP per capita is one of the lowest in the Western hemisphere (Table 1). Nonetheless, Cuba, unlike most Latin American countries, has achieved health outcomes comparable with those of the United States (Table 1).

A number of studies describe and analyze the Cuban health system at a structural level ${ }^{1,5-13}$; no studies to date have focused on what family physicians can learn and apply at an individual level. Substantially changing the US health system at a structural level is a slow process at best and is virtually impossible for most family physicians. Therefore, after a brief review of literature on the Cuban health system structure, this article will focus on 2 aspects of Cuban family medicine- community-oriented primary care (COPC) and complementary and alternative medicine (CAM).

\section{Structure of the Cuban Health System}

Health care was nationalized after the 1959 Cuban revolution. Health care statistics from before the 
Table 1. Comparison of Health Statistics and Gross National Product Cuba vs United States and other Latin American Countries $^{3}$

\begin{tabular}{lcccc}
\hline Country & $\begin{array}{c}\text { Life Expectancy } \\
\text { at Birth }\end{array}$ & $\begin{array}{c}\text { Maternal Mortality } \\
\text { (per 100,000 live births) }\end{array}$ & $\begin{array}{c}\text { Infant Mortality } \\
\text { (per 1,000 live births) }\end{array}$ & $\begin{array}{c}\text { Gross National Product } \\
\text { per Capita (US\$) }\end{array}$ \\
\hline Cuba & 76.3 & 34.1 & 7.2 & $2,270^{4}$ \\
United States & 77.2 & 7.1 & 7.2 & 31,910 \\
Haiti & 54.6 & 523.0 & 80.3 & 1,470 \\
Guatemala & 65.3 & 111.1 & 49.0 & 3,630 \\
\hline
\end{tabular}

Source: Pan American Health Organization, 2001

Cuban revolution in 1959 , reveal a national profile common to impoverished Third World countries. $^{6,14}$ The current model of primary health care evolved from evaluations conducted since the 1960s. Identified deficits that led to the current model are similar to those facing US health care providers today: emphasis on curative rather than preventive services; lack of collaboration within the health system; fragmented care; patient discontent related to the inconsistent quality of care; excessive use of emergency rooms; and shortages of primary care physicians. ${ }^{7}$

Today in Cuba, primary care is provided in consultorios (clinics), secondary care in policlinicos (specialty clinics), and tertiary care in hospitales and institutos (hospitals and medical institutes). Consultorios address approximately $80 \%$ of the health problems and emphasize health promotion. ${ }^{8}$

The current system of family medicine based in neighborhood consultorios (Figures 1 and 2) was established in 1984. Family physicians, paired with

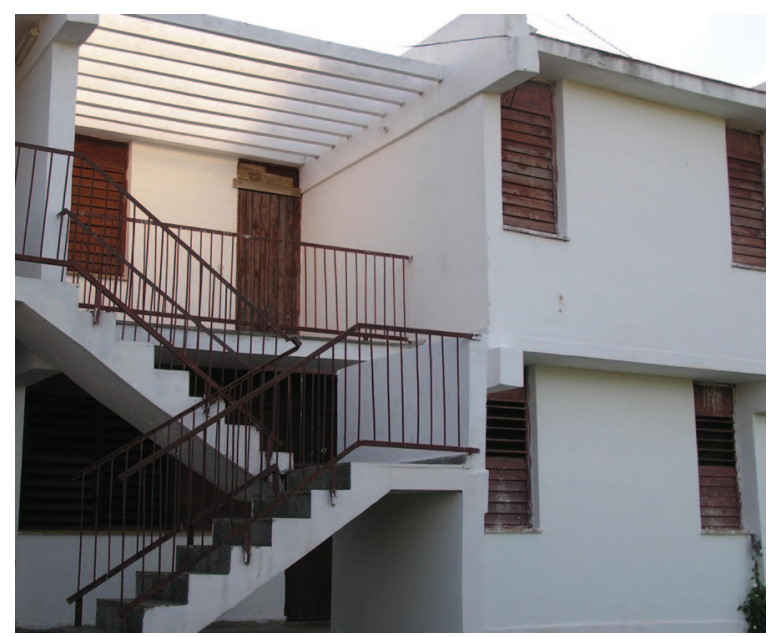

Figure 1. Exterior of typical consultorio (primary care clinic). nurses, serve approximately 600 patients or 150 families in a defined geographic area surrounding their consultorio. The family physician and nurse live in housing units adjacent to their consultorio and are integrated into the community they serve. ${ }^{5}$ Health promotion and disease prevention are emphasized, in that public health concepts are integrated with clinical practice. In the mornings, family physicians typically attend patients in their consultorio; "afternoons are reserved for home visits to patients with acute care needs, rehabilitation of chronic conditions, and primary prevention."

Patients requiring care beyond the scope of the consultorio are referred to a policlinico. Consisting of interdisciplinary teams, policlinicos offer specialty care in a variety of areas, usually including pediat-

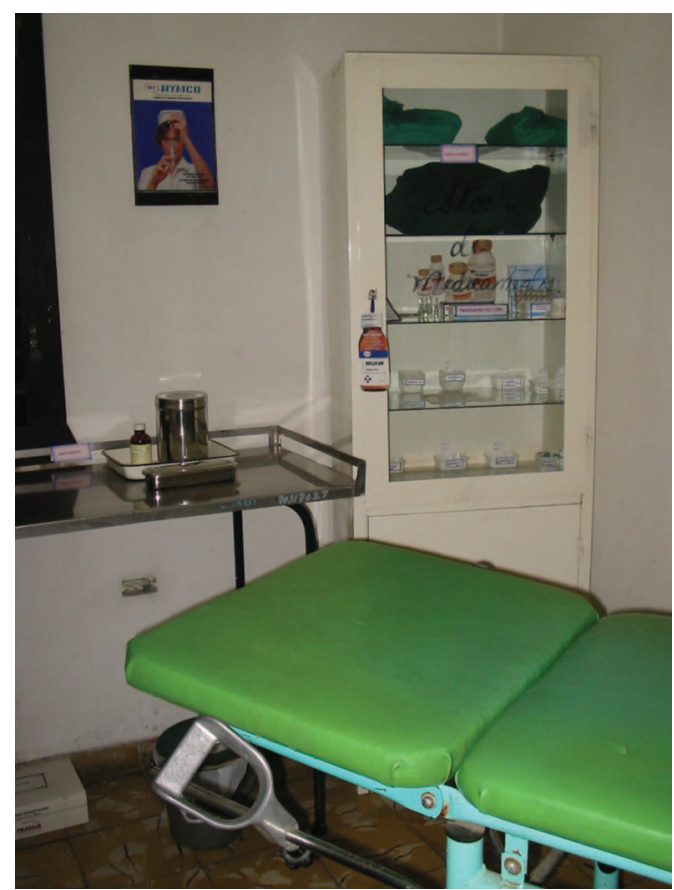

Figure 2. Interior of typical consultorio (primary care clinic). 
rics, internal medicine, nursing, social work, dentistry, and physical therapy, and sometimes including cardiology, pulmonology, ophthalmology, neurology, endocrinology, dermatology, and psychiatry. Much of what is called complementary and alternative medicine in the United States is designated "natural and traditional medicine" in Cuba and is increasingly available throughout the country. There are 440 policlinicos throughout Cuba, and each policlinico serves 30 to 40 consultorios. ${ }^{8}$ It is noteworthy that many family physicians spend a half-day per week joining their patients for specialist visits in policlinicos. This provides continuity for patients, builds collegial relationships between family physicians and specialists, and offers education for all parties involved.

\section{How Cuba's Outcomes Are Attained}

"Cuba's experience presents nothing less than a fundamental paradox or challenge to the assumption that generating wealth is the fundamental precondition for improving health." Although there is great interest in Cuba's impressive health outcomes, "there has been remarkably little scholarship evaluating how Cuba's successes have been achieved, let alone sustained during a period of extreme economic difficulty." "

Health outcomes are affected by nonmedical determinants, social mediators and health service determinants. Nonmedical determinants include education, housing, clean air, clean water, nutrition, and employment. Social mediators include social cohesion, income disparities, and other social structure inequalities. Health service determinants include accessibility, universality, comprehensiveness, quality, integration horizontally, primary care focus, integration across sectors (social, environmental focus, etc), and health promotion focus. ${ }^{9}$ No studies have demonstrated which of the above factors contributes the most to the health outcomes attained in Cuba.

A relative lack of large income disparities is a social mediator that may play an important role in the health outcomes that Cuba achieves.

The central assumption of the World Bank, the largest international health funding organization, is that economic growth is the most fundamental prereq- uisite for alleviating poverty and improving health.

However, "data suggest that growth that enhances disparity will most likely generate more poor health." "In contrast with Cuba, "inequality has yielded different health outcomes throughout the United States depending on race, origin, and incomes of people." African-American infants in the United States are on average more than twice as likely to die in their first year than white babies: the infant mortality is 13.9 per 1000 live births for African Americans, compared with 6.4 for whites. ${ }^{10}$

The accessibility of family physicians is a health service determinant that probably contributes to Cuba's health outcomes. Family practice is the foundation of the medical practice in Cuba today. Practically all graduates of medical school are currently required to complete a family practice residency. ${ }^{6}$ Cuba has the highest family physician-topopulation ratio in the world, ${ }^{11}$ and it has a family physician-per-patient ratio of approximately $1: 600 .^{8}$ In the United States, the average family physician-per-population ratio is approximately $1: 3200 .{ }^{15}$ In 2001 , only $35 \%$ of Cuban residency graduates specialized further (including $8 \%$ who graduated in general internal medicine and pediatrics). ${ }^{16}$ In the United States, only a third of physicians are primary care physicians (ie, family practice, internal medicine, and pediatrics physicians). ${ }^{17}$ Only $11 \%$ are family physicians. ${ }^{18}$

The universality of health insurance in Cuba but not the United States is worth highlighting. "The United States is the only developed country that does not have a public medical security system to cover all citizens universally." 10

The high percentage of professionally attended births may be an important factor in Cuba's low maternal death rate. In Cuba, close to $100 \%$ of deliveries are professionally attended. ${ }^{10}$ History has shown that the presence of skilled birth attendants is a key factor in bringing down the number of maternal deaths. Of the 46 countries in which trained professionals attend $90 \%$ or more of births, only 5 have maternal deaths rates above 100 per 100,000 live births. In the industrialized countries, $99 \%$ of births are professionally attended. Somalia, the country with the lowest percentage of professionally attended births (2\%), has a maternal mortality rate of 1600 per 100,000 births. Next on the chart are Afghanistan and Nepal, both with $9 \%$ of 
births attended by a skilled professional and with maternal death rates of 1700 and 1500 , respectively. ${ }^{19}$

Cuba demonstrates that

achieving and maintaining a healthy population with good health results does not necessarily depend on a big budget or richness of a country. Good governmental policies regarding public health and social security are crucial to achieve a good quality of life equally distributed to the whole population. ${ }^{10}$

Elsewhere in the world, such as Kerala, India, "policies favoring equality have also produced impressive health outcomes."

\section{Methods}

To gain firsthand insight into family medicine in Cuba, we traveled legally to Cuba through MEDICC, an organization which administers medical rotations in Cuba. Similar "short-course" MEDICC rotations are no longer possible because of new US travel restrictions imposed beginning June 30, 2004.

We prepared for our trip with a literature search, reading, and discussions. In Cuba, we met with family physicians, nurses, public health officials, medical educators, and complementary medicine providers as we toured seventeen health care facilities in Camaguey, Nuevitas, and Havana.

\section{Results/Discussion}

We found the practice COPC and the use of CAM to be 2 characteristics of Cuban family physicians that US family physicians might consider incorporating into their practices. Whether or not these are key factors in Cuba's health outcomes, they have already been recommended by US professional organizations and are worth emulating.

\section{Community-Oriented Primary Care}

$\mathrm{COPC}$ is a

systematic approach to health care based on principles derived from epidemiology, primary care, preventive medicine and health promotion that has been shown to have positive benefits for communities in the United States and worldwide. $^{20}$

In the United States,

because of lack of predictable reimbursement for COPC services and difficulties encountered incorporating $\mathrm{COPC}$ in medical and residency curricula, widespread application of COPC has not occurred. ${ }^{20}$

In contrast, $\mathrm{Cuba}$ is

one clear example in which COPC has been successfully implemented, and physicians are held accountable for health care outcome measures of the community members they serve. In Cuba, a growing cadre of family physicians is being trained to work as part of a health care team trained to provide health education and preventive services, offer comprehensive medical care, and conduct population based-research. Each team cares for 600 to 800 people in a system-oriented approach capitalizing on COPC principles. ${ }^{21}$

In Cuba, family physicians are required to look at patients in the context of family and community. Medical records are organized by family. Health statistics are recorded and reviewed on a regular basis. When consultorios lack technology, wall charts are used (Figure 3). As needs are identified, action

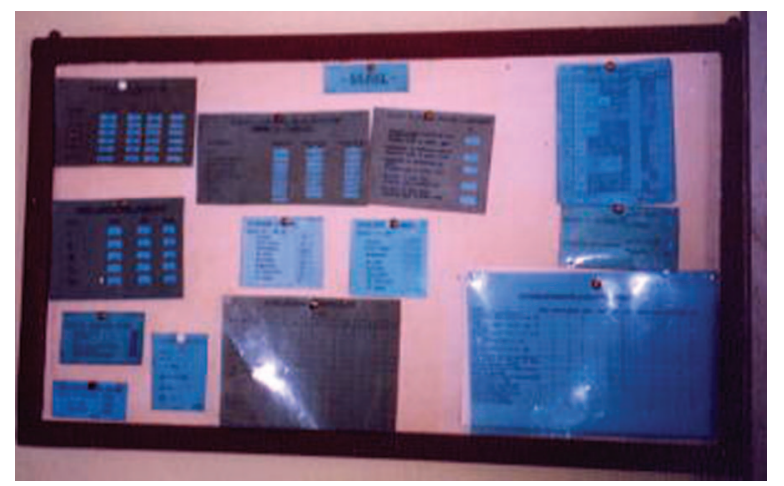

Figure 3. Epidemiologic data-including number of people with certain diseases, severity of diseases, birth outcomes and immunization rates-on wall of consultorio. 
plans are developed. Public health officials visit family physicians regularly to review and discuss their consultorio's health statistics.

Unless US physicians are

educated to look beyond the strict boundaries of medicine's traditional physician-patient dyad and until they are expected to assume a more comprehensive role as caregivers to families and communities, the true benefits of COPC will not be achieved. ${ }^{21}$

Recommendations from the Association of Family Practice Residency Directors (AFMRD) and others are available for US family medicine educators wanting to teach COPC to medical students and family practice residents. ${ }^{20}$

\section{Complementary and Alternative Medicine}

Family medicine has achieved "integrative medicine" to a greater extent in Cuba than in the United States. "Complementary medicine" is nonallopathic medicine used alongside conventional allopathic medicine. "Alternative medicine" is nonallopathic medicine used instead of conventional medicine. "Integrative medicine' results from the thoughtful incorporation of concepts, values and practices from alternative, complementary and conventional medicines." 22 In Cuba, these practices are known as "natural and traditional medicine."

In Cuba, family physicians learn the science of CAM in medical school. Students spend 200 hours in the first 2 years of medical school on CAM rotations (Figure 4). In addition, it is integrated into physiology, anatomy, and clinical courses. Ex-

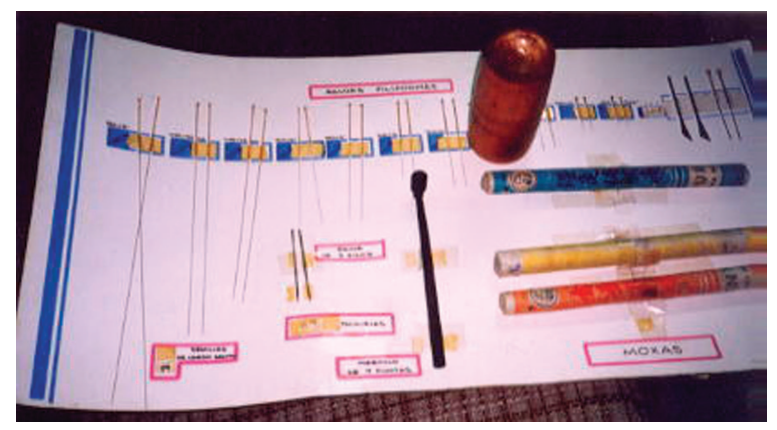

Figure 4. Instruments used for complementary and alternative medicine techniques at Carlos Finley Institute in Camaguey, Cuba. amples of CAM taught to Cuban physicians include acupuncture, herbal medicine, trigger point injections (Figure 5), massage, heat therapy, transcutaneous electrical nerve stimulation, magnetic therapy, pyramid therapy, moxibustion, fangotherapy (mud), cupping, laser/photograph therapy, floral/ essence therapy, homeopathy, yoga, meditation exercise training, and music and art therapy. Most family physicians in Cuba practice some herbal medicine, also known as "green medicine." A national formula and educational materials on green medicine are distributed to all practitioners by the Cuban Ministry of Public Health. ${ }^{12}$ In one example of herbal medicine used in the western part of Cuba, the bark of sassafras tree macerated in alcohol is applied topically to treat arthralgias. ${ }^{23} \mathrm{~A}$ family physician that we met practiced his own acupuncture. Family physicians refer to natural medicine clinics for therapies that they do not perform themselves.

Although most family physicians in the United States are not being trained in CAM, CAM is widely used by those living in the United States. Total out-of-pocket expenditures for CAM in the United States have been conservatively estimated to be $\$ 27$ billion. $^{24}$ CAM use is more common in recent years: approximately $30 \%$ of respondents in the pre-"Baby Boom" cohort, $50 \%$ in the Baby Boom cohort, and $70 \%$ in the post-Baby Boom cohort report using some type of CAM therapy by age $33 .{ }^{25}$ In a survey of physicians, $76 \%$ said their patients use CAM, and "the overwhelming majority (84\%) thought they needed to learn more about CAM to adequately address patient concerns."26

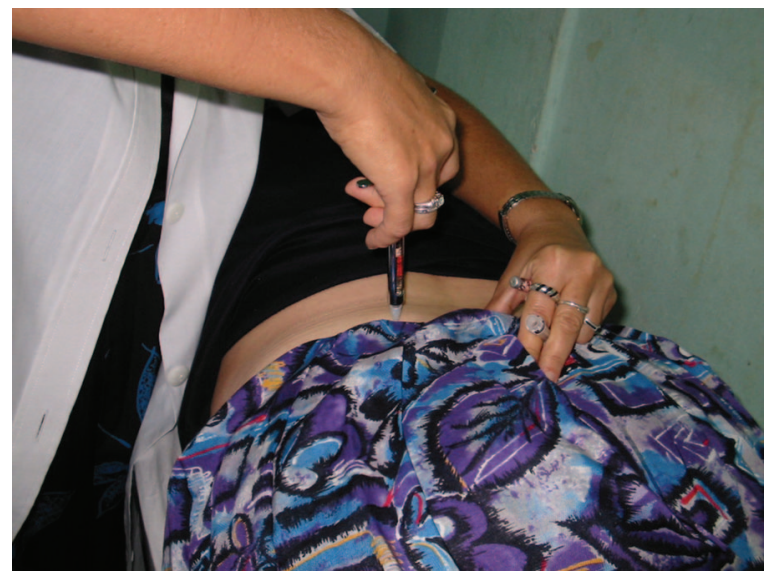

Figure 5. Trigger point injection. 
The extensive use of CAM by Cuban family physicians may be due, in part, to the current embargo and paucity of allopathic medicines. ${ }^{10}$ However, even in the United States, with its abundance of allopathic medicines, a need for greater familiarity with CAM by family physicians may be indicated, if for no other reason than to integrate what their patients are already doing outside the health care system into their current traditional care. As a step in this direction, the Society for the Teachers of Family Medicine (STFM) has developed curriculum guidelines for "programs wishing to include formal training in complementary and alternative medicine in residency training." ${ }^{27}$ Although more studies will be useful, there no longer is a need to wait for better studies before teaching CAM: the Cochrane database already includes over 5000 randomized, controlled trails involving CAM. ${ }^{28,29}$

\section{Conclusions}

Despite political differences, Cuba and the United States share a passion for baseball and for family medicine as an important component of the health care system. At a structural level, the Cuban and US health systems differ drastically: Cuba provides universal health insurance and every physician completes a family medicine residency. In contrast, the United States has more than 46 million uninsured residents, and only $11 \%$ of its physicians practice family medicine. Although individual US family physicians cannot easily change the structure of the health system, they can consider modifying their individual practices, learning from Cuban family physicians' successes with COPC and CAM. US family physicians wishing to add COPC and CAM to their practices can follow guidelines already established by AFMRD and STFM.

We acknowledge Bruce Barrett, MD, Cynthia Haq, MD, and Javier Nieto, MD, PhD (University of Wisconsin Medical School), for assistance with the preparation of the manuscript.

\section{References}

1. Hood RJ. Cuban Health System offers an uncommon opportunity. J Natl Med Assoc 2000;92:547-9.

2. World Health Organization [homepage on the Internet]. Geneva, Switzerland: World Health Organization; c2005 [updated 2005; cited 2005 Mar 19]. Core health indicators: Cuba; [about 3 screens]. Available from: http://www3.who.int/whosis/country/compare.cfm? country $=$ cub\&indicator $=$ strPcTotEOHinIntD2000\& language $=$ english.
3. Pan American Health Organization [homepage on the Internet]. Washington DC: Pan American Health Organization; c2005 [updated 2005; cited 2005 Mar 19]. Basic country health profiles for the Americas 2001; [about 2 screens]. Available from: http://www.paho.org/english/sha/profiles.htm.

4. Canadian International Development Agency [homepage on the Internet]. Gatineau, QC, Canada: Canadian International Development Agency, c2005 [updated 2005 Feb 7; cited 2005 Mar 19]. Cuba: facts at a glance; [about 6 screens]. Available from http:// www.acdi-cida.gc.ca/CIDAWEB/webcountry.nsf/ VLUDocEn/Cuba-Factsataglance.

5. Reed G. Challenges for Cuba's family doctor-andnurse program. MEDICC Review 2000;2:1-5.

6. Demers RY, Kembel S, Orris M, Orris P. Family practice in Cuba: evolution into the 1990s. Fam Pract 1993;10:164-8.

7. Diaz Novas J, Fernandez Sacasas J. From municipal polyclinics to family doctor-and-nurse teams. Revista Cubana de Medicina General Integral 1989;5: 556-64. Available from: http://www.medicc.org/ Medicc\%20Review/II/primary/poly.html

8. Sánchez L. Introducción a la Medicina General Integral. Selección de temas literatura básica. La Habana, Cuba: Editorial Ciencias Médicas 1999;10510.

9. Spiegel JM, Yassi A. Lessons from the margins of globalization: appreciating the Cuban health paradox. J Public Health Policy 2004;25:85-110.

10. Gutierrez SM, Mizota T, Rakue Y. Comparison of four health systems: Cuba, China, Japan and the USA, an approach to reality. Southeast Asian J Trop Med Public Health 2003;34:937-46.

11. Parsons LC, Barter M. Health care in Cuba: socialized medicine in a developing country. SCI Nurs 2001;18:142-7.

12. Waitzkin H, Wald K, Kee R, Danielson R, Robinson L. Primary care in Cuba: low- and high- technology developments pertinent to family medicine. J Fam Pract 1997;45:250-8.

13. Gilpin M. Cuba: on the road to a family medicine nation. Fam Med 1989;21:405-7, 462, 464.

14. Estadísticas de Salud de Cuba [homepage on the Internet]. Ciudad de La Habana, Cuba: Ministerio de Salud Pública de Cuba; c2000 [updated 2000; cited 2005 Mar 19]. Available from: http://www.dne. sld.cu/minsap/.

15. Colwill JM, Cultice JM. The future supply of family physicians: implications for rural America. Health Aff (Millwood) 2003;22:190-8.

16. Centro Nacional de Información de Ciencias Medicas [homepage on the Internet] Ciudad de La Habana, Cuba: Centro Nacional de Información de Ciencias Medicas; c2000 [updated 2000; cited 2005 Mar 19]. Portal de salud de Cuba: formación de personal calificado; [about 4 screens]. Available from http://www.sld.cu/anuario/anu01/fpc86.htm. 
17. Vanselow NA. Primary care and the specialist. JAMA 1998;279;1394-5.

18. Ramsey AH, Haq C, Gjerde C, Rothenberg D. Career influence of an international health experience during medical school. Fam Med 2004;36:412-6.

19. Maternal and Newborn Health and Safe Motherhood Program. Coverage of maternity care, 1997. Geneva, Switzerland: World Health Organization; 1997.

20. Longlett SK, Kruse JE, Wesley RM. Communityoriented primary care: critical assessment and implications for resident education. J Am Board Fam Pract 2001;14:141-7.

21. Ventres $W$, Hale F. Community-oriented primary care: the Cuban plan. JAMA 1993;270:1548.

22. Barrett B, Marchand L, Scheder J, et al. Themes of holism, empowerment, access, and legitimacy define complementary, alternative, and integrative medicine in relation to conventional biomedicine. $\mathrm{J} \mathrm{Al-}$ tern Complement Med 2003;9:937-47.

23. CUBA Fitomed III. Ciudad de La Habana, Cuba: Dirección Nacional de Ciencia y Técnica, Ministerio de Salud Pública; 1994.
24. Eisenberg DM, Davis RB, Ettner SL, et al. Trends in alternative medicine use in the United States, 1990-1997: results of a follow-up national survey. JAMA 1998;280:1569-75.

25. Kessler RC, Davis RB, Foster DF, et al. Long-term trends in the use of complementary and alternative medical therapies in the United States. Ann Intern Med 2001;135:262-8.

26. Corbin Winslow L, Shapiro H. Physicians want education about complementary and alternative medicine to enhance communication with their patients. Arch Intern Med 2002;162:1176-81.

27. Kligler B, Gordon A, Stuart M, Sierpina V. Suggested curriculum guidelines on complementary and alternative medicine: recommendations of the Society of Teachers of Family Medicine Group on Alternative Medicine. Fam Med 2000;32:30-3.

28. Wetzel MS, Kaptchuk TJ, Haramati A, Eisenberg DM. Complementary and alternative medical therapies: implications for medical education. Ann Intern Med 2003;138:191-6.

29. The Cochrane Library [database on disk and CDROM]. The Cochrane Collaboration. Oxford: Update Software; 2005. 